\title{
IL-6 and IL-8 Production from Cultured Human Endothelial Cells Stimulated by Infection with Rickettsia conorii via a Cell-associated

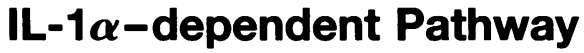

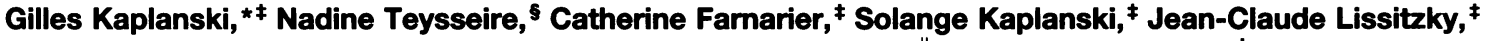 \\ Jean-Marc Durand, * Jacques Soubeyrand, * Charles A. Dinarello," and Pierre Bongrand” \\ * Service de Médecine Interne, ${ }^{\ddagger}$ Laboratoire d'Immunologie-INSERM U 387, Hôpital Sainte-Marguerite, 13009 Marseille, France; \\ ${ }^{\S}$ Unité des Rickettsies, Faculté de Médecine, Boulevard Jean Moulin, 13005 Marseille, France; and "Department of Medicine, \\ Division of Geographic Medicine and Infectious Diseases, New England Medical Center, Boston, Massachusetts 02111
}

\begin{abstract}
Mediterranean spotted fever due to infection by Rickettsia conorii, is characterized by a general vasculitis. This vasculitis is thought to be due to a direct injury to endothelial cells induced by $\boldsymbol{R}$. conorii. However, production and activity of cytokines on endothelial cells is an important pathway in inflammation, and part of the underlying mechanism of vasculitis. In the present studies, human umbilical vein endothelial cells (HUVEC) infected with $R$. conorii actively secrete high levels of IL-8 and IL-6 $(P<0.002$, and $P<0.03$, respectively, compared with uninfected cells). IL-1 $\alpha$, IL$1 \beta$, or TNF $\alpha$ were not detected in the culture supernates. Nevertheless, IL-6 and IL-8 production was due, in a large part, to a cell-associated form of $I L-1 \alpha$ expressed on $R$. conorii-infected HUVEC, since production of these cytokines was suppressed by $80 \%(P=0.0001)$ and $85 \%(P$ $<0.04)$ by the addition of $\mathrm{LL}-1$ receptor antagonist, or antiIL-1 $\alpha$ antibodies (60\% inhibition, $P<0.01$ and $65 \%$ inhibition, $P<0.05$, respectively) and IL-1 $\alpha$ was measured after lysis of $R$. conorii-infected HUVEC but not in uninfected cells $(P<0.01)$. Rickettsial lipopolysaccharide does not seem to be involved, since polymyxin $B$ did not reduce cytokine secretion. On the contrary, infection by intracellular $R$. conorii appears to be necessary to induce $I L-1 \alpha$ and subsequently IL-8, since formalin-fixed $R$. conorii did not induce cytokine production. These observations demonstrate that $R$. conorii-infected HUVEC secrete IL-6 and IL-8 via the induction of cell-associated IL-1 $\alpha$, providing a possible mechanism for the vasculitis observed in Mediterranean spotted fever. (J. Clin. Invest. 1995. 96:2839-2844.) Key words: Mediterranean spotted fever - Rickettsia conorii • vasculitis ・ IL-8 • IL-1
\end{abstract}

\section{Introduction}

Vasculitis constitutes an excellent example of disease due to an inflammatory reaction, characterized by the local accumulation

Address correspondence to Gilles Kaplanski, M.D., Ph.D., Laboratoire d'Immunologie-INSERM U 387, Hôpital Sainte-Marguerite, 270 Boulevard de Sainte-Marguerite, 13009 Marseille, France. Phone: 91-77-30651; FAX: 91-75-73-28.

Received for publication 22 October 1993 and accepted in revised form 8 September 1995.

J. Clin. Invest.

(C) The American Society for Clinical Investigation, Inc.

0021-9738/95/12/2839/06 \$2.00

Volume 96, December 1995, 2839-2844 of leukocytes and fluid at an extravascular site of injury (1). These phenomena are likely the result of pluripotent soluble mediators, and the subsequent expression of adhesion molecules on the surface of leukocytes and endothelial cells (1). Among these mediators, the cytokines IL- $1 \alpha, \mathrm{IL}-1 \beta$, TNF $\alpha$, and IL-8 appear to play a major role. IL- 1 and TNF $\alpha$ increase the expression of adhesion molecules on both leukocytes and endothelial cells, and also induce the production of other cytokines, such as IL-6 and IL-8 $(2,3)$. IL-6 increases the secretion of acute phase proteins, stimulates B cell, and induces IL-2 secretion and IL-2 receptor ( $p$ 55) expression, leading to proliferation and differentiation of T cells (4). IL-8 is a member of the chemokine family, a group of structurally related proteins with pro-inflammatory properties $(5)$. IL-8 is a potent chemotactic agent for polymorphonuclear cells (PMN) in vivo $(6,7)$, and for lymphocytes in vitro (8). IL-8 activates PMN functions and favors their migration across the endothelial cells monolayer $(9-11)$.

Spotted fevers due to rickettsioses are characterized by generalized vasculitis (12). Among these diseases, Mediterranean spotted fever (MSF) ${ }^{1}$ and Rocky Mountain spotted fever (RMSF) are closely related. MSF is due to infection by Rickettsia conorii, whereas RMSF is due to Rickettsia rickettsii (13). The first description of MSF was made in Tunisia, and this disease is also endemic in the south of France $(12,14)$. MSF is clinically characterized by fever, rash, and a lesion around the entry site called "tache noire" $(12,15)$. MSF like RMSF can be complicated in some patients and lead to death $(12,16)$. Histological examination of biopsies of MSF and RMSF reveals a vasculitis with increased vascular permeability, accumulation of PMN, followed by an infiltration of monocytes and lymphocytes $(17,18)$. Indeed, both $R$. conorii and $R$. rickettsii enter and proliferate in endothelial cells inducing cell death. This endothelial injury is thought to increase vascular permeability, and believed to be the underlying mechanism of $R$. conorii-induced vasculitis (19). In vitro, endothelial infection by $R$. conorii induces changes in cell behavior such as increased vascular permeability (20), the release of von Willebrand factor and expression of tissue factor (21-23), alteration of the tissue plasminogen activator-plasminogen activator inhibitor ratio (24), and increased platelet adhesion $(25,26)$. Moreover, the ability of $R$. rickettsii to induce E-selectin expression and PMN adhesion on endothelial cells has been recently reported (27). These effects could be mediated by cytokines;

1. Abbreviations used in this paper: HUVEC, human umbilical vein endothelial cell; MSF, Mediterranean spotted fever; RMSF, Rocky Mountain spotted fever. 
however, there is no study on the putative effects of rickettsial endothelial infection on cytokine production. In the present studies, we asked whether infection of endothelial cells by $R$. conorii results in the production of inflammatory cytokines, especially IL-8, IL-1 and TNF $\alpha$.

\section{Methods}

Materials. The following materials were purchased: M199 culture medium (Flow Laboratories, ICN, Orsay, France); RPMI 1640 culture medium and L-glutamine (Bio-Whittaker, Fontenay sous Bois, France); penicillin G, streptomycin, bovine skin gelatin, trypsin-EDTA, endothelial supplement growth factor from bovine pituitary gland, polymyxin B sulfate, sodium azide (NaN3), PMSF, NP-40 (Sigma Chemical Co. Coger, Paris, France); FCS (Eurobio, Les Ulis, France); human recombinant IL- $\alpha$, rabbit anti-human IL-1 $\beta$ polyclonal antibody (Genzyme, Dako, Le Perray en Yvelines, France). For inhibition experiments, a rabbit anti-human IL- $1 \alpha$ polyclonal antibody was used as previously described (28). IL-1 receptor antagonist (IL-1Ra) was a gift of Dr. D. E. Tracey (Upjohn Co, Kalamazoo, MI).

Cell cultures. Human umbilical vein endothelial cells (HUVEC) were obtained as previously described (29), and used on passage 2 . Cells were grown until confluent in 24-well plates coated with $1 \%$ gelatin. The cells were then cultured in RPMI containing $10 \%$ heatinactivated FCS, $100 \mathrm{U} / \mathrm{ml}$ penicillin $\mathrm{G}, 100 \mu \mathrm{g} / \mathrm{ml}$ streptomycin. Before each experiment, endothelial growth factor was withheld for $48 \mathrm{~h}$ and the cells cultured in the same medium containing 5\% FCS for $24 \mathrm{~h}$. HUVEC were then washed twice in RPMI containing $10 \%$ heat-inactivated FCS without antibiotics or endothelial growth factor, and incubated with $200 \mu \mathrm{l}$ of the $R$. conorii inoculum for $1 \mathrm{~h}$, at $37^{\circ} \mathrm{C}$. HUVEC were then washed three times in antibiotic-free RPMI $10 \%$ heat-inactivated FCS, and $500 \mu \mathrm{l}$ of the same medium were added to each well. In some experiments, either IL-1Ra at various concentrations, polyclonal antibodies against IL- $1 \alpha(10 \mu \mathrm{g} / \mathrm{ml}$ final dilution $)$ or IL- $1 \beta(40 \mu \mathrm{g} / \mathrm{ml}$ final dilution), were added to the culture. After different culture times, the supernatant from each well was collected, centrifuged, and stored at $-75^{\circ} \mathrm{C}$ before assay. To solubilize the cell membranes, in some experiments, HUVEC were lysed using a solution containing PBS, 100 $\mathrm{mM}$ NP-40, $10 \mathrm{mM} \mathrm{NaN}_{3}, 10 \mathrm{mM}$ PMSF, pH 7.5.

R. conorii preparation. $R$. conorii ("7") strain VR617 from the American Type Culture Collection, Rockville, MD) were grown in Vero cells (kidney, African green monkey) as previously described (22). When Vero cells were highly infected, they were harvested using glass beads, and used to inoculate HUVEC. The titer of infectivity of the inoculum was determined on serially diluted cultures by an indirect immunofluorescence technique using an anti- $R$. conorii rabbit antibody $(1 / 200$ in PBS ) and goat anti-rabbit antibody conjugated to fluorescein isothiocyanate (FITC, 1/200 in PBS) (Immunotech, Marseille, France). Titers ranged from $8 \times 10^{4}$ to $5 \times 10^{5}$. In some experiments, infection was performed with formalin-fixed $R$. conorii. Fixation was accomplished by incubating infected Vero cells in antibiotic-free RPMI $10 \%$ heat-inactivated FCS culture medium containing $0.1 \%$ formaldehyde during $24 \mathrm{~h}$. The fixative was removed by three successive washes. As a negative control, HUVEC were cultured in the presence of uninfected Vero cells harvested using the same procedures and materials as those used for the inoculum.

Cytokine assays. IL-8 was measured using a specific ELISA (Biotra, Amersham, Les Ulis, France); IL- $1 \alpha$ and IL- 6 were measured using an ELISA from Immunotech (Marseille, France). IL- $1 \beta$ and TNF $\alpha$ were measured using specific RIAs (IRMA, Medgenix, ERIA Pasteur, Paris, France).

Statistical analysis. Cytokine levels were expressed as the mean \pm SEM of results obtained from 3 to 6 individual experiments. In each experiment, duplicate wells were assayed separately for each condition for cytokine production. The data were compared using paired Student's $t$ test.
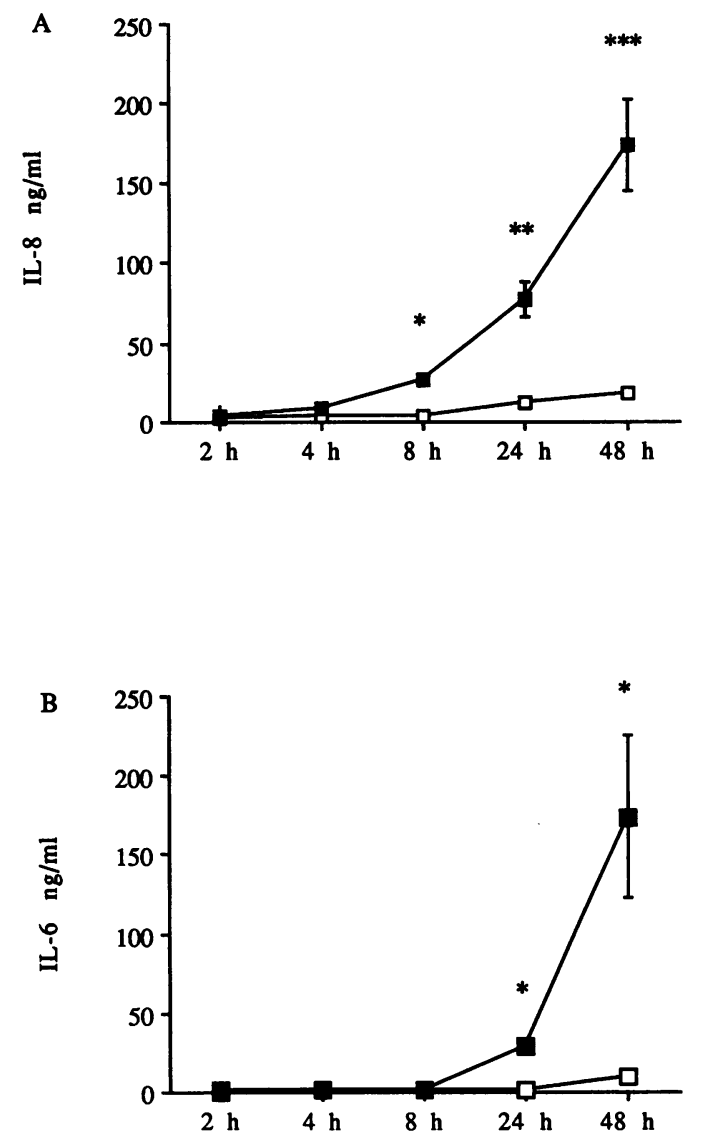

Figure 1. Kinetics of $R$. conorii-infected HUVEC cytokine secretion. $(A)$ IL-8 and $(B)$ IL-6. HUVEC were infected with $R$. conorii (filled squares) and IL-8 and IL- 6 were measured after different times of culture. As a negative control, HUVEC were cultured with lysed uninfected Vero cells (open squares). Results are expressed as the mean \pm SEM of six experiments $(* P<0.03, * * P<0.002, * * * P$ $<0.0001$, compared with the negative control).

\section{Results}

$R$. conorii-infected HUVEC secrete IL-8 and IL-6. Infection of HUVEC by $R$. conorii induced the secretion of nanogram amounts of IL-8 (Fig. $1 \mathrm{~A}$ ), compared with the negative control $(* P<0.03, * * P=0.002, * * * P=0.0001$, respectively). Culture of HUVEC with lysed uninfected Vero cells was chosen for a negative control since $R$. conorii were grown in Vero cells and lysates of Vero cells were therefore present in $R$. conoriiinfected HUVEC culture. Under these conditions, production of a low but significant amount of IL-8 (Fig. $1 \mathrm{~A}$ ) was observed, compared with HUVEC cultured in medium alone (data not shown). IL-8 secretion by $R$. conorii-infected HUVEC was time-dependent, reaching significance after $6-8 \mathrm{~h}$ of culture, and consistently increasing until $48 \mathrm{~h}$. Similarly, $R$. conoriiinfected HUVEC produced large amounts of IL-6 (Fig. $1 \mathrm{~B}$ ). This IL- 6 secretion was time-dependent and became significant after $24 \mathrm{~h}$ of culture ( $* P=0.03$, compared with the negative control).

Endothelial IL-8 and IL-6 production is blocked by IL-1Ra. To identify a possible role of IL-1 in endothelial production of IL- 8 and IL- 6 induced by $R$. conorii infection, $R$. conorii-infected HUVEC were cultured in the presence of IL-1Ra (Fig. 


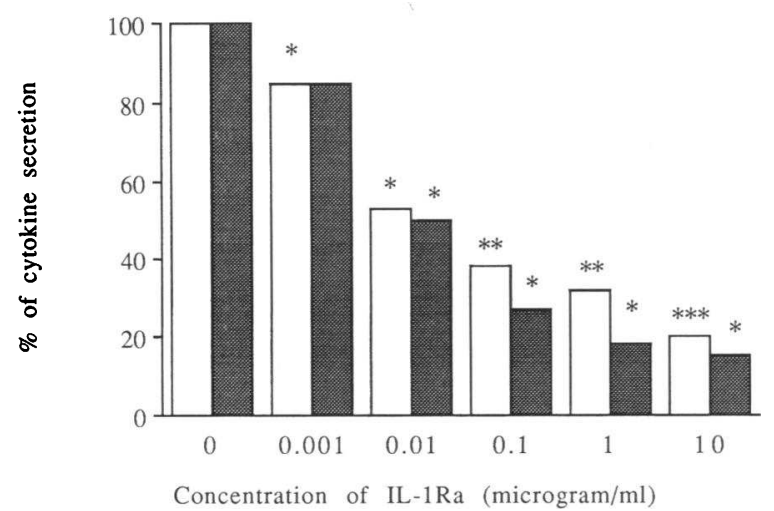

Figure 2. Inhibitory effect of IL-1Ra on IL-8 and IL-6 production by $R$. conorii-infected HUVEC. HUVEC were infected with $R$. conorii, then cultured in the absence (100\%) or in the presence of various concentrations of IL-1Ra. IL-8 (open bars, $n=6$ ) and IL-6 (filled bars, $n=3$ ) were measured after $24 \mathrm{~h}$ culture. Results are expressed as percentage of the cytokines produced when $R$. conorii-infected HUVEC are cultured in the absence of IL-1Ra, $100 \%\left(* P<0.05,{ }^{* *} P\right.$ $<0.01, * * * P<0.001$, compared with $100 \%)$.

2). Both IL-8 (open bars) and IL-6 (filled bars) production by R. conorii-infected HUVEC were inhibited by IL-1Ra in a dosedependent fashion reaching a maximum of $80 \%$ for IL-8 production $(P=0.0001, n=6)$ and $85 \%$ for IL-6 production ( $P$ $=0.04, n=3)$ with $\mathrm{IL}-1 \mathrm{Ra}$ at $10 \mu \mathrm{g} / \mathrm{ml}\left(* P<0.05,{ }^{*} P\right.$ $<0.01, * * * P<0.001$ compared with $R$. conorii-infected HUVEC without IL-1Ra, 100\%)

$I L-6$ and $I L-8$ production are blocked by anti-IL-1 $\alpha$, but not anti-IL-1 $\beta$ antibodies. IL-8 (Fig. $3 \mathrm{~A}$ ) and IL-6 (Fig. $3 \mathrm{~B}$ ) secretion by $R$. conorii-infected HUVEC were inhibited by antiIL- $1 \alpha$ antibodies (60\% inhibition, $* P<0.01$ and $65 \%$ inhibition, ${ }^{*} P<0.05$, respectively). On the contrary, anti-IL- $1 \beta$ antibodies had no significant effect on both $R$. conorii-infected HUVEC IL-8 secretion (Fig. $3, \mathrm{RC}=65 \pm 3 \mathrm{ng} / \mathrm{ml} ; \mathrm{RC}+$ anti$\mathrm{IL}-1 \beta \mathrm{Ab}=61 \pm 7 \mathrm{ng} / \mathrm{ml}, P=\mathrm{ns}, n=3)$ and IL-6 secretion $(\mathrm{RC}=33 \pm 4 \mathrm{ng} / \mathrm{ml}, \mathrm{RC}+$ anti-IL- $\beta \mathrm{Ab}=35 \pm 1 \mathrm{ng} / \mathrm{ml}, P$ $=\mathrm{ns}, n=3$ ).

Detection of $I L-1 \alpha$ in infected-HUVEC lysates using an ELISA. To understand the mechanisms of reducing IL-6 and IL- 8 production by IL-1Ra, we measured IL-1 levels in the cultures of $R$. conorii-infected HUVEC. IL- $1 \beta$ and TNF $\alpha$ were not detected in the supernatant of $R$. conorii-infected HUVEC, at different times of culture (levels below the assay detection limits, i.e., $50 \mathrm{pg} / \mathrm{ml}$ for IL- $1 \beta ; 5 \mathrm{pg} / \mathrm{ml}$ for TNF $\alpha$ ). Similarly, no significant IL-1 $\alpha$ was found in the supernatant (Vero $=15 \pm 15 \mathrm{pg} / \mathrm{ml}, \mathrm{RC}=35 \pm 15 \mathrm{pg} / \mathrm{ml}$ after $24 \mathrm{~h}, P=\mathrm{ns}, n$ $=6$, assay detection limit: $15 \mathrm{pg} / \mathrm{ml}$ ). On the other hand, after cell-membranes were solubilized in a solution containing a detergent and anti-protease, a significant amount of IL- $1 \alpha$ was found from cells infected with $R$. conorii, but not in control HUVEC cultured with Vero cells $(323 \pm 30 \mathrm{pg} / \mathrm{ml}$ after $24 \mathrm{~h}$, $* P=0.01$, Fig. 4). The expression of cell-associated IL- $1 \alpha$ on HUVEC was time-dependent, increasing during the first 24 h (Fig. 4).

IL-1 $\alpha$ induces IL-8 secretion by HUVEC. We studied the amount of exogenous IL- $1 \alpha$ necessary to induce the same $24 \mathrm{~h}$ production of IL-8 by HUVEC as $R$. conorii-infected HUVEC. As shown in Fig. $5,>500 \mathrm{pg} / \mathrm{ml}$ of IL- $1 \alpha$ were necessary to induce amounts of IL-8 comparable in magnitude to those ob-
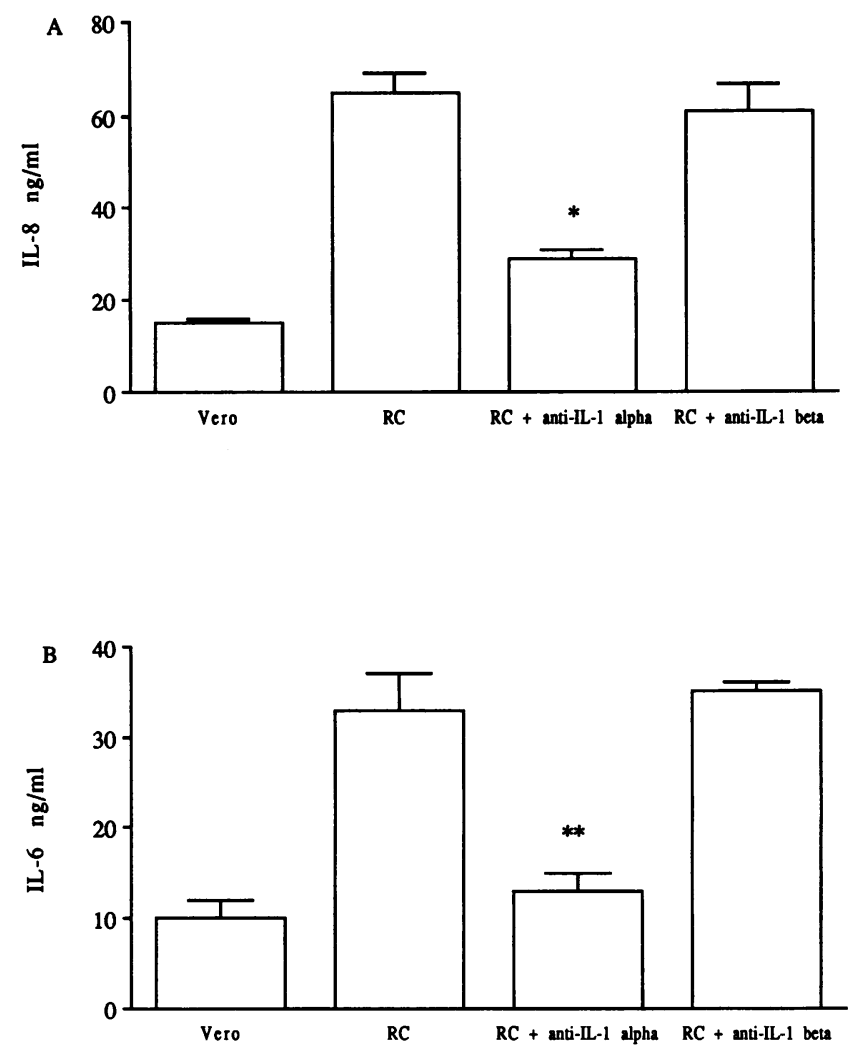

Figure 3. Effects of anti-IL- $1 \alpha$ and anti-IL-1 $\beta$ antibodies on IL-8 and IL-6 secretion from $R$. conorii-infected HUVEC. HUVEC were infected with $R$. conorii, then cultured in the absence (RC) or in the presence of anti-IL- $1 \beta$ antibodies at $40 \mu \mathrm{g} / \mathrm{ml}$ final dilution (RC + anti-IL$1 \beta$ ) or anti-IL- $1 \alpha$ antibodies (RC + anti-IL- $1 \alpha$ ) at $10 \mu \mathrm{g} / \mathrm{ml}$ final antibody dilution. IL-8 $(A)$ and IL-6 $(B)$ were measured after $24 \mathrm{~h}$ culture. Vero represents the negative control. Results are expressed as the mean \pm SEM of three different experiments $(* P<0.01, * * P$ $<0.05$, compared with $\mathrm{RC}$ ).

tained with $R$. conorii-infected HUVEC ( $* P<0.05$, **P $<0.01$ compared with HUVEC cultured without IL- $1 \alpha$ ).

$I L-1 \alpha$ and $I L-8$ production are not due to $R$. conorii $L P S$, but require live $R$. conorii. To assess the role of rickettsial LPS in endothelial IL-8 secretion, we infected HUVEC in the presence of polymyxin B. Under these conditions, no significant decrease in either IL-8 secretion (9\% reduction compared with $\mathrm{RC}$ without polymyxin B, Fig. 6 ) or IL-6 secretion ( $8 \%$ reduction, data not shown) could be detected. Moreover, formalinfixed $R$. conorii were not able to induce IL- $1 \alpha$ nor IL-8 production by HUVEC. ( $P<0.003$ in comparison with unfixed RC, i.e., $100 \%$, Fig. 6 ; and data not shown).

\section{Discussion}

To date, the vasculitis associated with MSF was thought to be due to a direct endothelial injury induced by $R$. conorii. In this study, we showed that HUVEC infected by $R$. conorii actively secrete large amounts of IL- 8 and IL- 6 via an IL-1 dependent pathway. There was an $80 \%$ reduction in IL-8 secretion and an $85 \%$ reduction in IL-6 secretion when HUVEC were treated with IL-1 Ra or anti-IL- $1 \alpha$ antibodies. Cell-associated IL- $1 \alpha$, but not IL- $1 \beta$ appears to be responsible for IL-8 and IL- 6 induction. 


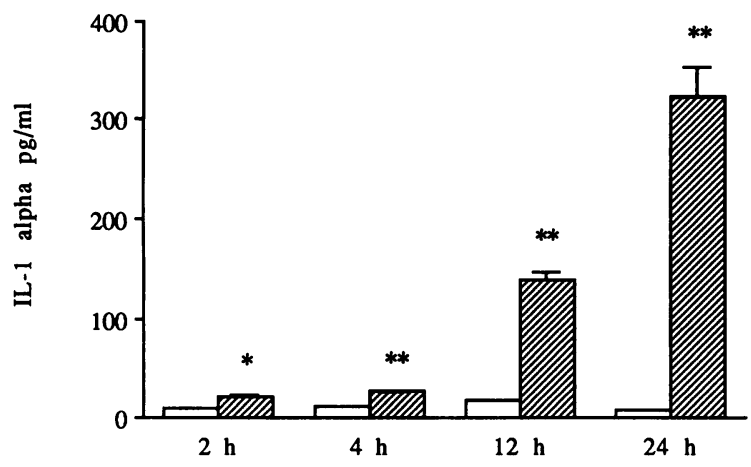

Figure 4. Detection of cell-associated IL- $1 \alpha$ in $R$. conorii-infected HUVEC lysates using an ELISA. HUVEC were either cultured with Vero cells (open bars) or infected with $R$. conorii (hatched bars) for different times. Cells were lysed and membranes solubilized in presence of detergent and antiprotease before being assayed for IL- $1 \alpha$. Results are expressed as the mean \pm SEM of three experiments $(* P<0.05, * * P$ $<0.01$ compared with HUVEC cultured with Vero)

Numerous reports studying the effects of Rickettsia infection have failed to demonstrate a role for soluble factors such as cytokines, mainly because the supernatants of Rickettsia-infected HUVEC showed no stimulatory activity when added to uninfected cells $(21,27)$. However, almost all changes in cell behavior observed after HUVEC $R$. conorii or $R$. rickettsii infection, such as tissue factor induction (22), von Willebrand factor release $(21,22)$ or $E$ selectin expression (27) might be due to IL-1 or TNF $\alpha(30,31)$. The inhibitory effect of IL-1Ra on infected HUVEC IL-8 and IL- 6 production demonstrates that IL-1 plays the major role as the inducer, whereas TNF $\alpha$, although secreted by monocytes infected with $R$. conorii (32), does not seem to be involved. Neither IL- $1 \beta$, nor IL- $1 \alpha$, however, could be found in the supernatants of HUVEC, in agreement with previous reports $(21,27)$. When $R$. conoriiinfected HUVEC membranes, however, were solubilized, a significant amount of IL- $1 \alpha$ was measured. Using western blotting, we found that a $23-\mathrm{kD}$ immunoreactive IL- $1 \alpha$, possibly representing only partially processed form of the biologically active IL-1 $\alpha$ precursor (33), was induced in $R$. conorii-infected HU-

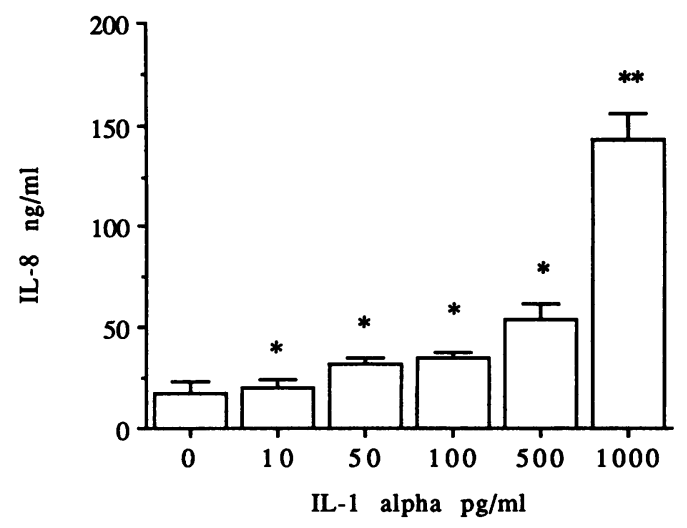

Figure 5. IL-1 $\alpha$ induces IL-8 secretion by HUVEC. Increasing concentrations of IL- $1 \alpha$ were added to HUVEC and IL- 8 was measured in the supernatants after $24 \mathrm{~h}$. Results are expressed as the mean \pm SEM of three experiments $(* P<0.05, * * P<0.01$, compared with HUVEC cultured without IL-1 $\alpha$ ).

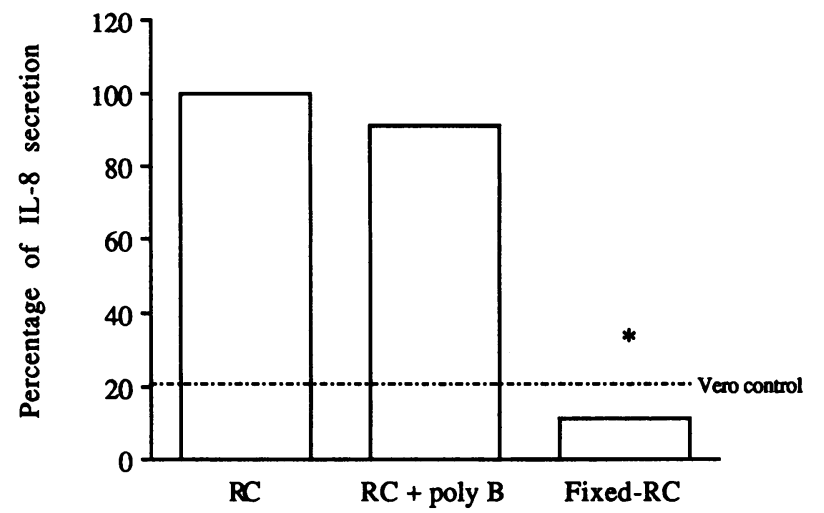

Figure 6. Effect of formalin-fixed $R$. conorii or polymyxin B treatment on IL-8 secretion from HUVEC. HUVEC were infected with either unfixed $R$. conorii, then cultured in absence (RC) or presence of polymyxin B ( RC + poly B); or with $R$. conorii previously fixed in formaldehyde (fixed-RC). The dashed line indicate levels of IL-8 secretion obtained with the negative Vero control (uninfected HUVEC with lysed Vero cells). IL-8 is expressed as percentage secretion of HUVEC infected with unfixed $R$. conorii in absence of polymyxin B (RC, 100\%) $(* P<0.003)$.

VEC but not in Vero control (data not shown). In addition, cytokine production by $R$. conorii-infected HUVEC was decreased by anti-IL- $1 \alpha$, but not by anti-IL- $1 \beta$ antibodies, clearly supporting IL- $1 \alpha$ production in these cultures.

IL- $1 \alpha$ produced by HUVEC remains associated with the cells (34). Although intracellular IL-1 $\alpha$ precursor can be transported in the nucleus of endothelial cells, and still be active (35), in the present studies, the effects of IL- $1 \alpha$ are not likely due to nuclear localization, since IL-1Ra blocked IL-6 and IL8 production by $R$. conorii-infected HUVEC. Hence IL-1Ra is blocking endothelial surface IL-1 receptors. Therefore, while not completely ruling out a role for intracellular IL- $1 \alpha$, these results suggest that IL-1 is most likely acting outside the cell.

IL- $1 \alpha$ precursor can be secreted by HUVEC and immediately bound to the type I IL- 1 receptor (36). Thus, IL- $1 \alpha$ can act as an autocrine factor on HUVEC, without being detectable in the supernatant (36) and this could account for the effects of IL- 1 in our experiments. Alternatively, IL- $1 \alpha$ can be active without being secreted. In LPS-stimulated monocytes the 31 $\mathrm{kD}$ precursor of IL- $1 \alpha$ and also a $23-\mathrm{kD}$ partially processed form of the IL- $1 \alpha$ precursor are acylated $(33,37)$ and associated with the cell membrane in a biologically active form. An active form of IL- $1 \alpha$ precursor has been reported on HUVEC membranes (38). The activity of one cell's membrane-associated cytokine towards a target cell has been described for such molecules as transforming growth factor $\alpha$, fibroblast growth factor, and platelet activating factor under the name of juxtacrine (39$41)$. We recently demonstrated that IL- $1 \alpha$ fixed on monocyte surface membranes can induce IL-8 secretion by HUVEC (42). Usually, cells involved in a cell-cell interaction are heterophilic (for example leukocytes and endothelial cells) (41), in the case of endothelial cells, it is conceivable that the producer and the target cells are adjacent endothelial cells, since these cells grow in monolayers. IL-1 could then be said to act as a "juxtacrinelike" factor. A similar observation has been previously reported for IL- $1 \alpha$ on the surface of smooth muscle cells which can induce IL- 6 secretion by contact with other smooth muscle cells 
(43). From the present study however, we do not know which mechanism or whether both mechanisms are taking place.

Since LPS is a potent stimulus of IL-1 and other cytokines, we asked whether bacterial LPS was involved in our experiments. Rickettsial-derived LPS could not have accounted for cytokine production, since polymyxin B did not affect the production of IL-8 or IL-6. In addition, formalin-fixed $R$. conorii, which have lost their ability to enter and proliferate in HUVEC (44), did not induce IL-8 secretion. Although fixation might have changed the conformation of some components on $R$. conorii surface, fixed-Rickettsia are still able to adhere to HUVEC (44). Our observations thus suggest that adherence of $R$. conorii to the cell membrane is not sufficient to signal these events. This is in agreement with the fact that $R$. conorii is an obligate intracellular organism, and with other reports showing for example, that prostaglandin secretion by infected HUVEC, does not occur when Rickettsia are fixed (44).

IL-8 and IL- 6 secreted by $R$. conorii-infected HUVEC might play a role in the development of the vasculitis of MSF. IL-8 is a potent chemotactic agent for PMN and lymphocytes at nanomolar and picomolar concentrations, respectively (5-8). IL-8 stimulates PMN secretion and transendothelial migration (9-11), but does not seem to have any effect on endothelial cells $(45,46)$. Biopsies of patients with MSF show that this vasculitis is mainly composed of $\mathrm{T}$ lymphocytes and monocytes. In animals, however, where biopsies are made early in the course of the disease, necrotic vasculitis with PMN infiltration is observed during the first $3 \mathrm{~d}$ after infection (18). Later, lymphocytes and monocytes become predominant. This relative discrepancy between the animal and the human lesion is probably due to the fact that patients are biopsied late after the onset of the disease, usually not before the fourth day (15). Indeed, in human volunteers, $6 \mathrm{~h}$ after intradermal injection of $R$. prowazekii, skin biopsies show the presence of a PMN infiltrate (17). Moreover, there is a potential role of PMN in the vasculitis associated with RMSF, a disease closely related to MSF. HUVEC infected with $R$. rickettsii, the agent of RMSF, express high levels of E-selectin molecules, leading to a significant increased adhesion of PMN to HUVEC (27). Our results suggest that after this first step of adhesion molecules expression on HUVEC, for which IL-8 is not responsible (46), IL-8 might be active in enhancing PMN adhesion, favoring transendothelial PMN migration in vessels.

IL-6 also secreted by $R$. conorii-infected HUVEC may mediate the acute phase protein production associated with MSF $(4,12)$. Furthermore, after the first days of infection, mononuclear cells, especially $T$ lymphocytes, predominate in the perivascular infiltrate, and may participate in the control of infection $(17,18,47)$. IL-6 might be implicated in the local differentiation and proliferation of $\mathrm{T}$ lymphocytes, through its effects on IL-2 and IL-2 receptor in T cells (48).

We conclude from this study that the vasculitis associated with $R$. conorii infection may be due to an active secretion of cytokines. We propose that after the tick-bite, $R$. conorii induces IL- $1 \alpha$ production by HUVEC, which in turn, induces the expression of adhesion molecules and the secretion of chemoattractants, such as IL-8 via an autocrine mechanism. Each of these conditions are required for PMN adhesion to the infected endothelial cells, and development of the necrotic neutrophilic vasculitis, observed in the first days of $R$. conorii infection. In a second step, a monocyte and lymphocyte response could appear in order to control the infection; IL-6 production might play an important role through its effects on $\mathrm{T}$ cells proliferation and differentiation.

\section{Acknowledgments}

This work was supported by the Assistance Publique de Marseille, and by the National Institute of Health Grant 15614 (to C. A. Dinarello). We thank Drs. D. Raoult, J. Sampol and F. George for useful discussions.

\section{References}

1. Pober, J. S., and R. S. Cotran. 1990. The role of endothelial cells in inflammation. Transplantation. 50:537-544.

2. Dinarello, C. A. 1991. Interleukin-1 and interleukin-1 antagonism. Blood. 77:1627-1652.

3. Beutler, B., and A. Cerami. 1989. The biology of cachectin/TNF, a primary mediator of host response. Ann. Rev. Immunol. 7:625-655.

4. Hirano, T., S. Akira, T. Taga, and T. Kishimoto. 1990. Biological and clinical aspects of interleukin 6. Immunol. Today. 11:443-449.

5. Baggiolini, M., B. Dewald, and B. Moser. 1994. Interleukin-8 and related chemotactic cytokines CXC and CC chemokines. Adv. Immunol. 85:97-179.

6. Peveri, P. A., A. Walz, B. Dewald, and M. Baggiolini. 1988. A novel neutrophil-activating factor produced by human mononuclear phagocytes. J. Exp. Med. 167:1547-1559.

7. Thelen, M. P., P. Peveri, P. Kernen, V. von Tscharner, A. Walz, and M Baggiolini. 1988. Mechanism of neutrophil activation by NAF, a novel monocytederived peptide agonist. FASEB J. 2:2702-2706.

8. Larsen, C. G. A. O Anderson, E. Appella, J. J. Oppenheim, and K. Matsushima. 1989. The neutrophil-activating protein (NAP-1) is also chemotactic for T lymphocytes. Science (Wash. DC). 243:1464-1466.

9. Smith, W. B., J. R. Gamble, I. Clarck-Lewis, and M. A. Vadas. 1991 Interleukin-8 induces neutrophil transendothelial migration. Immunology. 72:6572.

10. Huber, A. R., S. L. Kunkel, R. F. Todd, and S. J. Weiss. 1991. Regulation of transendothelial neutrophil migration by endogenous interleukin-8. Science (Wash. DC). 254:99-102.

11. Kuijpers, T. W., B. C. Hakkert, H. L. Hart, and D. Roos. 1992. Neutrophil migration across monolayers of cytokine-prestimulated endothelial cells: a role for platelet-activating factor and IL-8. J. Cell Biol. 117:565-572.

12. Raoult, D., and D. H. Walker. 1990. Rickettsia rickettsii and spotted fever group rickettsiae (Rocky mountain spotted fever and other spotted fevers). In Principles and Practice of Infectious Diseases. G. L. Mandell, R. G. Douglas, Jr. and J. E. Benett, editors. Churchill Livingstone, New York. 1465-1471.

13. Winkler, H. H. 1990. Rickettsia species (as organisms). Ann. Rev. Microbiol. 44:131-153.

14. Conor, A., and A. Bruch. 1910. Une fièvre éruptive observée en Tunisie. Bull. Soc. Pathol. Exot. 3:492-496.

15. Walker, D. H., C. Occhino, G. R. Tringall, S. Di Rosa, and S. Mansueto. 1988. Pathogenesis of rickettsial eschars: the tache noire of boutonneuse fever. Hum. Pathol. 19:1449-1454.

16. Vicente, V., I. Alberca, R. Ruiz, I. Herrero, R. Gonzalez, and J. Portugal. 1986. Coagulation abnormalities in patients with Mediterranean spotted fever. $J$. Infect. Dis. 153:128-131.

17. Dumler, J. S., and C. I. Wisseman, Jr. 1992. Preliminary characterization of inflammatory infiltrates in response to Rickettsia prowazekii reinfection in man: immunohistology. Acta Virol. 36:45-51.

18. Walker, D. H., N. G. Watkins, J. S. Dumler, and S. Vishwanath. 1992. Experimental skin lesion (tache noire) in guinea-pigs after intradermal inoculation of Rickettsia conorii. Immunol. Infect. Dis. 2:51-59.

19. Silverman, D. J. 1984. Rickettsia rickettsii-induced cellular injury of human vascular endothelium in vitro. Infect. Immun. 44:545-553.

20. Ruiz, R., J. I. Herrero, A. M. Martin, F. Sanz, A. Mateos, A. Hernandez, R. Querol, and J. Portugal. 1984. Vascular permeability in boutonneuse fever. $J$. Infect. Dis. 149:1036.

21. Sporn, L. A., R. S. Shi, S. O. Lawrence, D. J. Silverman, and V. J. Marder. 1991. Rickettsia rickettsii infection of cultured endothelial cells induce release of large von Willebrand factor multimers from Weibel-Palade bodies. Blood. 78:2595-2602.

22. Teysseire, N., D. Arnoux, F. George, J. Sampol, and D. Raoult. 1992. Von Willebrand factor release and thrombomodulin and tissue factor expression in Rickettsia conorii-infected endothelial cells. Infect. Immun. 60:4388-4393.

23. Raoult, D., D. Arnoux, M. Drancourt, and J. P. Ardissone. 1987. Enzyme secretion by human endothelial cells infected with Rickettsia conorii. Acta. Virol. 31:352-356.

24. Drancourt, M., M. C. Alessi, P. Y. Levy, I. Juhan-Vague, and D. Raoult. 1990. Secretion of tissue-type plasminogen activator and plasminogen activator 
inhibitor by Rickettsia conorii- and Rickettsia rickettsii-infected cultured endothelial cells. Infect. Immun. 58:2459-2463.

25. Rao, A. K., M. Schapira, M. L. Clements, S. Niewiarowski, A. Z. Budzynski, A. Shmaier, P. C. Harpel, W. C. Blackwelder, J. R. Scherrer, E. Sobel, and R. W. Colman. 1988. A prospective study of platelets and plasma proteolytic systems during the early stages of rocky mountain spotted fever. N. Engl. J. Med. 318:1021-1028.

26. Silverman, D. J. 1986. Adherence of platelets to human endothelial cells infected by Rickettsia rickettsii. J. Infect. Dis. 153:694-700.

27. Sporn, L. A., S. O. Lawrence, D. J. Silverman, and V. J. Marder. 1993. Eselectin-dependent neutrophil adhesion to Rickettsia rickettsii-infected endothelial cells. Blood. 81:2406-2412.

28. Dinarello, C. A., T. Ikejima, S. J. C. Warner, S. F. Orencole, G. Lonnemann, J. G. Cannon, and P. Libby. 1987. Interleukin 1 induces interleukin 1 . I. Induction of circulating interleukin 1 in rabbits in vivo and in human mononuclear cells in vitro. J. Immunol. 139:1902-1910.

29. Kaplanski, G., R. Porat, K. Aiura, J. K. Erban, J. A. Gelfand, and C. A. Dinarello. 1993. Activated platelets induce endothelial secretion of interleukin-8 in vitro via an interleukin-1-mediated event. Blood. 81:2492-2495.

30. Bevilacqua, M. P., J. S. Pober, G. R. Majeau, R. S. Cotran, and M. A. Gimbrone. 1984. Interleukin 1 (IL-1) induces biosynthesis and cell surface expression of procoagulant activity in human vascular endothelial cells. J. Exp. Med. 160:618-623.

31. Schorer, A. E., C. F. Moldow, and M. E. Rick. 1987. Interleukin 1 or endotoxin increases the release of von Willebrand factor from human endothelial cells. Br. J. Haematol. 67:193-197.

32. Manor, E., and I. Sarov. 1990. Tumor necrosis factor alpha and prostaglandin $\mathrm{E} 2$ production by human monocyte-derived macrophages infected with spotted fever group rickettsiae. Ann. NY Acad. Sci. 590:157-167.

33. Bakouche, O., J-L. Moreau, and L. B. Lachman. 1991. Acylation of cellassociated IL-1 by palmitic acid. J. Immunol. 147:2164-2169.

34. Poubelle, P. E., J. Grassi, P. Pradelles, and F. Marceau. 1989. Pharmacological modulation of interleukin 1 production by cultured endothelial cells from human umbilical veins. Immunopharmacology. 19:121-130.

35. Maier, J. A. M., M. Statuto, and G. Ragnotti. 1994. Endogenous interleukin 1 alpha must be transported to the nucleus to exert its activity in human endothelial cells. Mol. Cell. Biol. 14:1845-1851.

36. Cozzolino, F., M. Torcia, D. Aldinucci, M. Ziche, F. Almerigogna, D. Bani, and D. M. Stern. 1990. Interleukin 1 is an autocrine regulator of human endothelial cell growth. Proc. Natl. Acad. Sci. USA. 87:6487-6491.
37. Stevenson, F. T., S. L. Burstein, C. Fanton, R. M. Locksley, and D. H. Lovett. 1993. The 31-kDa precursor of interleukin $1 \alpha$ is myristoylated on specific lysines within the $16-\mathrm{kDa}$ N-terminal propiece. Proc. Natl. Acad. Sci. USA. 90:7245-7249.

38. Kurt-Jones, E. A., W. Fiers, and J. S. Pober. 1987. Membrane interleukin 1 induction on human endothelial cells and dermal fibroblasts. J. Immunol. 139:2317-2324.

39. Massagué, J. 1990. Transforming growth factor- $\alpha$. A model for membraneanchored growth factor. J. Biol. Chem. 265:21393-21396.

40. Anklesaria, P., J. Teixido, M. Laiho, J. Pierce, J. S. Greenberger, and J. Massagué. 1990. Cell-cell adhesion mediated by binding of membrane-anchored transforming growth factor $\alpha$ to epidermal growth factor receptors promotes cell proliferation. Proc. Natl. Acad. Sci. USA. 87:3289-3293.

41. Lorant, D E K. D. A. Patel, T M. McIntyre, R. P. McEver, S. M. Prescott, and G. A. Zimmerman. 1991. Coexpression of GMP-140 and platelet activating factor by endothelium stimulated by histamine or thrombin: a juxtacrine system for adhesion and activation of neutrophils. J. Cell. Biol. 115:223-234.

42. Kaplanski, G., C. Farnarier, S. Kaplanski, R. Porat, L. Shapiro, P. Bongrand, and C. A. Dinarello. 1994. Interleukin-1 induces interleukin-8 secretion from endothelial cells by a juxtacrine mechanism. Blood. 84:4242-4248.

43. Loppnow, H., and P. Libby. 1992. Functional significance of human vascular smooth muscle cell-derived interleukin 1 in paracrine and autocrine regulation pathways. Exp. Cell. Res. 198:283-290.

44. Walker, T. S., J. S. Brown, C. S. Hoover, and D. A. Morgan. 1990 Endothelial prostaglandin secretion: effects of typhus rickettsiae. J. Infect. Dis. 162:1136-1144.

45. Carveth, H. J., J. F. Bohnsack, T. M. McIntyre, M. Baggiolini, S. M. Prescott, and G. A. Zimmerman. 1989. Neutrophil activating factor (NAF) induces polymorphonuclear leukocyte adherence to endothelial cells and to subendothelial matrix proteins. Biochem. Biophys. Res. Commun. 162:387-393.

46. Luscinskas, F. W., J-M. Kiely, H. Ding, M. S. Obin, C. A. Hébert, J. B. Baker, and M. A. Gimbrone Jr. 1992. In vitro inhibitory effect of IL-8 and other chemoattractants on neutrophil-endothelial adhesive interactions. J. Immunol. 149:2163-2171.

47. Dumler, S. J., C. L. Wisseman, Jr., P. Fiset, and M. L. Clements. 1992. Cell-mediated immune responses of adults to vaccination, challenge with Rickettsia rickettsi, or both. Am. J. Trop. Med. Hyg. 46:105-115.

48. Renauld, J-C., A. Vink, and J. Van Snick. 1989. Accessory signals in murine cytolytic T cell responses. Dual requirement for IL-1 and IL-6. J. Immunol. 143:1894-1898. 